\title{
GONZALO HALFFTER SALAS, DOCTOR HONORIS CAUSA POR LA UNIVERSIDAD DE ALICANTE
}

\section{Cuadernos de Biodiversidad}

El pasado 23 de noviembre de 2000, el ecólogo mexicano D r. G onzal o $\mathrm{H}$ alffter Salas fue investido como D octor H onoris C ausa por la U niversidad de Alicante en el transcurso de una solemne ceremonia académica que tuvo lugar en el Paraninfo de esta universidad, habiendo tenido como padrino al profesor D. Eduardo G alante, director del CIBIO (Centro Iberoamericano de la Biodiversidad). Fue este acto el reconocimiento de la comunidad universitaria de la U niversidad de Alicante a la labor de toda una vida dedicada al estudio y conservación del medio, como señaló su padrino en el laudatio pronunciado anteel claustro universitario, presidido por el Excmo. y M agco. Sr. Rector Prof. Andrés Pedreño, y que contó con la presencia del IImo. Sr. D irector de Enseñanzas Universitarias de la Comunidad Valenciana, Prof. Salvador Forner.

EI D r. Gonzalo H alffter Salas nació en M adrid en 1932. Nacionalizado en M éxico, es licenciado en biología y doctor en Ciencias. $\mathrm{H}$ a ocupado ininterrumpidamente varias cátedras, la D irección de los D epartamentos de Biología y Zoología, así como la Dirección de Graduados e Investigación Científica de la Escuela $\mathrm{N}$ acional de Ciencias Biológicas del Instituto Politécnico Nacional de M éxico y en la actualidad tiene la máxima posición académica que otorga dicha institución universitaria. Entre sus numerosos méritos podemos destacar el haber sido fundador y director del Instituto deEcología, A.C., cuya sedeprincipal seencuentra en Xalapa (Veracruz, $\mathrm{M}$ éxico); director del $\mathrm{M}$ useo de $\mathrm{H}$ istoria $\mathrm{N}$ atural de la Ciudad de M éxico y D irector Adjunto de D esarrollo Científico del Consejo $\mathrm{N}$ acional deCiencia y
Tecnología. Asimismo ha sido Presidente del Consejo Internacional de Coordinación del Programa MAB-UNESCO, Presidente del Advisor and Committeefor Biosphere Reserves, U NESCO y en la actualidad es el presidente del Comité M exicano de dicho Programa M AB y Coordinador Internacional del SubprogramaXII: «DIVERSID AD BIO LÓ GICA» del Programa I beroamericano de Ciencia y Tecnología para el D esarrollo (CYTED -D).

Posee numerosas distinciones entre las que destacan el Special Award of Recognition of the United States $\mathrm{N}$ ational $\mathrm{Committee} \mathrm{for} \mathrm{M}$ an and Biosphere (1980); la Condecoración de O ficial de la O rden del M érito, otorgada por el Presidente de la República Francesa (1984); D octor H onoris Causa por la Universidad de París, (1984); Profesor Emérito del Instituto Politécnico N acional (1986); la medaIla Alfonso L. H errera al M érito en Ecología y C onservación (1986); el Reconocimiento Especial otorgado por el Presidente de los Estados U nidos M exicanos por su «nvaluable Aportación al Conocimiento de la Diversidad Biológica en M éxico y por su Contribución $\mathrm{H}$ istórica a la Conservación y al U so Sustentable del Patrimonio N atural deN uestro País» (Ciudad de M éxico a 5 de junio de 1996); o el Premio al M érito Ecológico de la Secretaría del M edio Ambiente y Recursos N aturales y Pesca (1997).

Su elevada producción científica se extiendea 288 trabajos de investigación, de los cuales 52 son libros o capítulos de libro.

El acto de investidura se enmarcó en la celebración del I Foro Iberoamericano de Biodiversidad organizado por el CIBIO (22 y 24 de noviembre de 


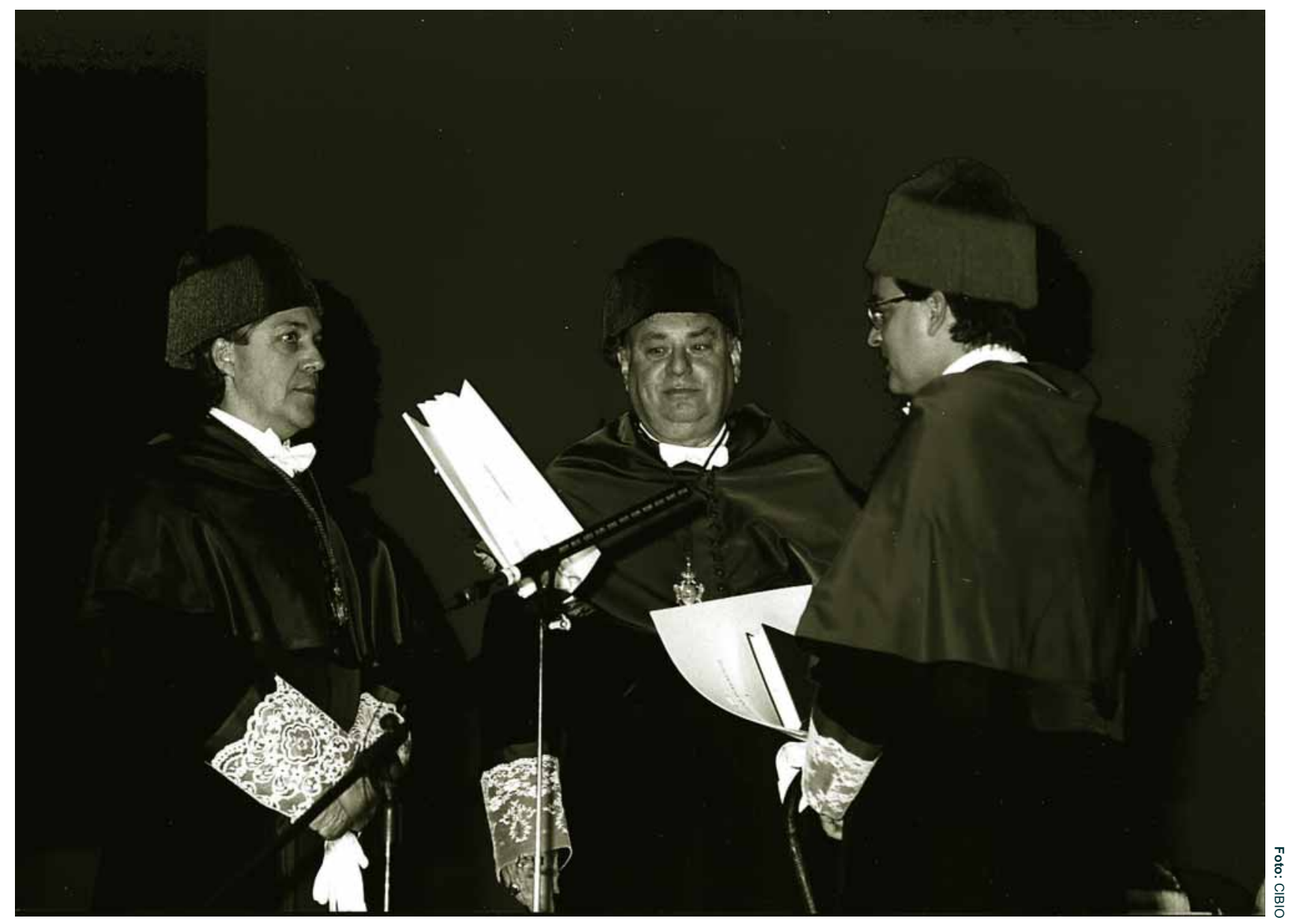

EI D r. Gonzalo H alffter junto a su padrino, el D r. Eduardo GalantePatiño, anteel Secretario General dela U niversidad deAlicante, en un momento de la solemne investidura.

2000). Fue un acto de reconocimiento a un excelente biólogo que ha trabajado durante largos años en el campo del comportamiento animal, la biogeografía y la conservación de recursos biológicos. D esu amplia labor como científico, su padrino el D r. Galante, destacó entre otros el mérito de haber desarrollado el concepto de «Reservas de la Biosfera», figura de protección del medio que incorporó a la estrategia de conservación los aspectos socioeconómicos locales y regionales, basado todo ello en una sólida información científica.

A su vez, el Dr. H alffter destacó en su discurso de ingreso en el claustro de doctores de la Universidad de Alicante, y entre otras cosas, la necesidad de impulsar la investigación en el seno de las universidades, huyendo de corrientes que abogan a veces por reducir a las instituciones universitarias a meros centros docentes y constreñir la labor investigadora a cuestiones puramentetecnológicas, afirmando «sin universidades y centros de investigación, el desarrollo económico e incluso las libertades democráticas están en situación frágil».

D esde este momento, la Universidad de Alicante se ha engrandecido un poco más, y todos los que pertenecemos a ella nos sentimos extremadamente honrados, al contar entrenuestro claustro con el $D r$. G onzalo H alffter Salas. 